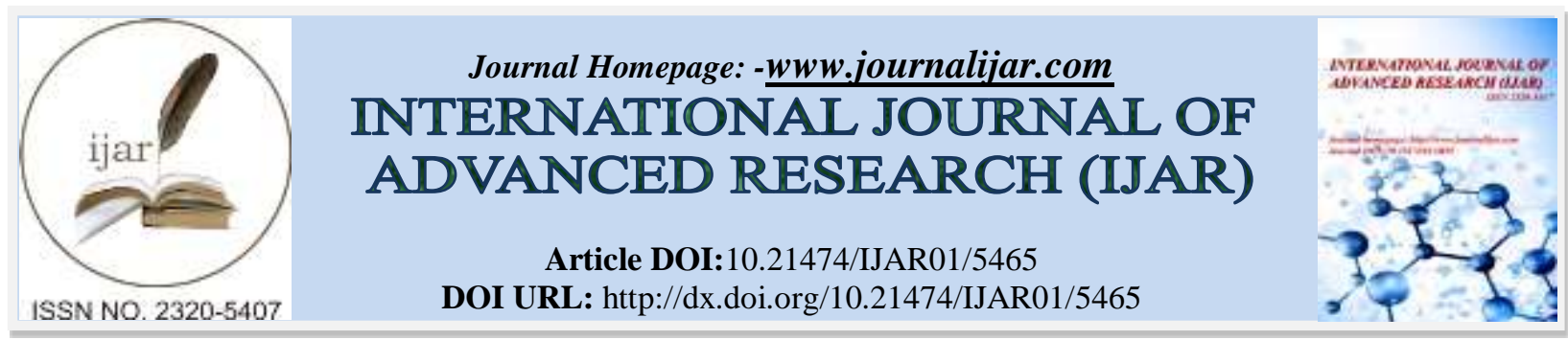

RESEARCH ARTICLE

\title{
MANAGEMENT AND OUTCOME IN HIGH GRADE RENAL TRAUMA IN SERIES OF 30 CASES.
}

Dr. V. Gomathi ${ }^{1}$ M.S. M.Ch, Dr. R. Maniappan ${ }^{2}$ M.Ch, Resident, Prof. Dr. J. Muthukumaran ${ }^{3}$ M. S. M.Ch

1. Assistant Professor, Dept of Paediatric Surgery, Institute of child health ,Egmore, Chennai.

2. MCh Resident, Dept of Paediatric Surgery, Institute of child health ,Egmore, Chennai.

3. Professor, HOD, Dept of Paediatric Surgery, Institute of child health ,Egmore, Chennai

\section{Manuscript Info}

Manuscript History

Received: 18 July 2017

Final Accepted: 20 August 2017

Published: September 2017

Key words:-

CECT, IV pyeologram, renorraphy, DJ

stenting.

\section{Abstract}

Grade 1 and 2 renal injuries treated conservatively. Grade 3,4,5 treated with renorraphy, nephrectomy, DJ stenting, perinephric drain tailored to the needs of the patients. All patient was evaluated with clinical signs and symptoms, USG, IV pyeologram, CECT abdomen. Grading of injury done by urologic injury scale of the American association.

Copy Right, IJAR, 2017,. All rights reserved.

\section{Introduction:-}

The study comprised of 30 children who were admitted and managed either conservatively or operated for high grade renal trauma.

Children are more prone for injury due to larger size when compared to adults, lower position in abdomen, decreased perirenal fat, less ossified thoracic rib cage. Renal fascia and gerota fascia are less developed in children.

Children sustained abdominal trauma by fall from height, wall collapse, seat belt injury and RTA were clinically examined and found to have the following signs and symptoms.

Symptoms:

1. Blood in penile meatus.

2. Loin and abdominal pain.

3. Vomiting.

4. Bruises in abdominal wall.

5. Shock.

\section{Investigation protocol:-}

Children presenting with blunt injury abdomen were resuscitated and then subjected to investigation as per trauma protocol. Screening xray of abdomen, chest, spine were taken and then followed with USG abdomen, IVP and CECT abdomen.USG detects perinephrich ematoma, single shot IVP after 10minutes of non ionic contrast detects collecting system injuries and CECT delineates parenchymal contusion, laceration, perinephric hematoma and urinary extravasation. Arterial injuries are identified by ANGIOGRAM.

All children were put on: 
Nil oral, IV Fluids, bladder catheterized and urine output monitored .Strict bed rest regular blood pressure and pulse were checked. Blood transfused if anemia and shock was present. 23 patients were treated conservatively as they had grade 1 and 2 injuries. Cystoscopy and DJ stenting done in 2 patients. Pelvi-ureteric anastomosis done in 2 patients where pelvi-ureteic junction was avulsed. Nephrectomy was done in one patient were renovascular injury was seen and kidney was shattered. Perinephreic drain kept in patients with perinephrichaematoma.

Fig .1 \& Fig.2:- CECT IMAGES: urinary extravasation due to PUJ avulsion

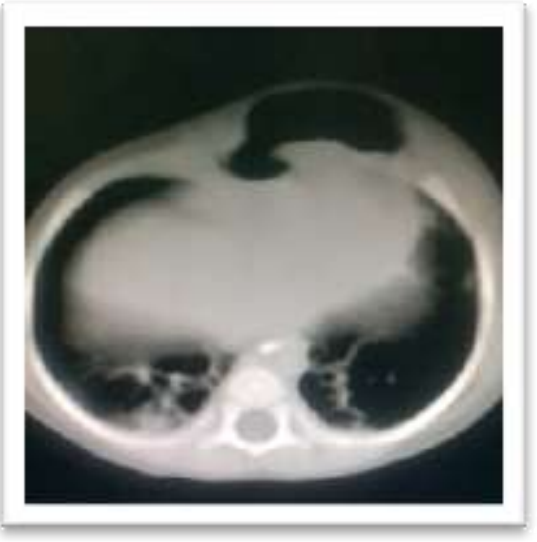

Fig.3:- IVP showing contrast filled kidneys

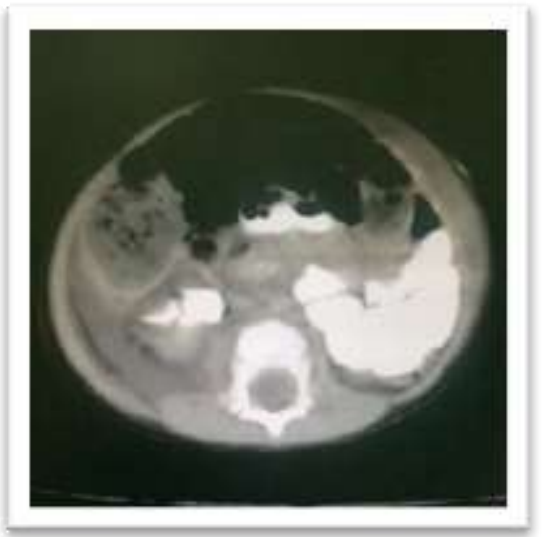

Fig.4:- Fluoroscopy showing contrast filled kidney and ureter

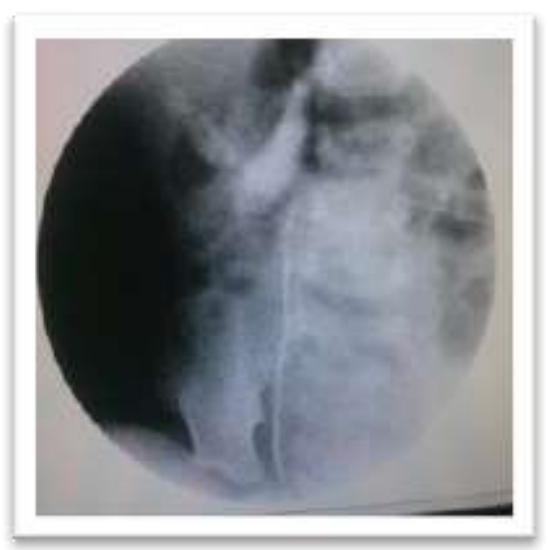

Fig.5:- Avulsed pelviureteic junction repaired over DJ stent.

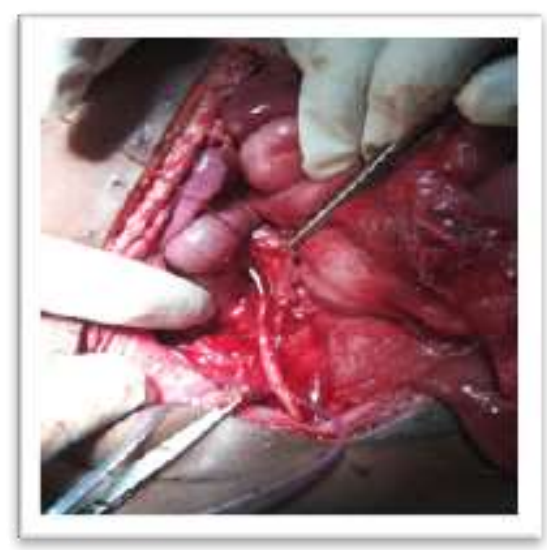




\section{Discussion:-}

Our study revealed good results in 28 patients and 2 patients died due to associated liver injury and bone injury.

\section{References:-}

1. Dalla renal injuries in children, AS 1998: 133 :490- 496

2. Cochrane $\mathrm{E}$ : two examples of children with renal injury. Med 1733: 1:203

3. Dawson L: high grade renal injury in children. Arch Ped 1901: 18:41

4. Vidal E : conservative management of renal trauma. ASFRCHIR 1905: 18:739

5. Jacobs MA Conservatively management Vs early surgery for high grade renal trauma- donephrectomy rates differ? J Urol May 2012, 1:644-645.

6. Baverstock R et al. Severe blunt renal trauma. CJU. 2013.179-180 